\title{
OCCURRENCE OF LEAF SPOT OF OAT CAUSED BY ALTERNARIA ALTERNATA IN MULTAN, PUNJAB, PAKISTAN
}

\author{
Ali Raza, Muhammad Afnan, Asghar Ali, Syed Atif Hasan Naqvi, Hameed Ullah Khan Sherwani, Muhammad \\ Nouman, Hafiz Muhammad Saqib \\ ${ }^{1}$ Department of Plant Pathology, Faculty of Agricultural Sciences and Technology, Bahauddin Zakariya University, Multan, \\ Pakistan.
}

\section{A R T I C L E I N F O}

\section{Article history}

Received: 30th July, 2018

Revised: $15^{\text {th }}$ October, 2018

Accepted: $15^{\text {th }}$ October, 2018

Keywords
Leaf spot
Alternaria alternate
Avena sativa
Disease incidence
Disease severity

\section{A B S T R A C T}

Oat (Avena stiva L.) is a fast growing and high yielding winter fodder crop. It is highly palatable, nutritious and energy rich fodder. Recently, the oat plantation at different locations of Multan was found to be suffered with a new type of leaf spot disease. Isolation from affected portions revealed consistent association of Alternaria alternata with this disease. In order to confirm the etiology of this disease, pathogenicity test was conducted on oat plants in greenhouse conditions with four different isolates of Alternaria alternata, which produced the similar symptoms, hence satisfied the Koch's postulates. Survey results showed that the maximum disease incidence of $51.99 \%$ was recorded from Band Bosan, followed by 43.33 , 31.33 and 27.66\% incidences at Raza Abad, Basti No and Lutfa Abad, respectively. Maximum severity of disease was recorded at Band Bosan (31.99\%), followed by Raza Abad (21.66\%), Basti No (11.33\%) and Lutfa Abad (7.33\%). To the best of our knowledge, this is the first report of Alternaria alternata causing leaf spot of oat.

Corresponding Author: Syed Atif Hasan Naqvi

Email:atifnaqvi@bzu.edu.pk

(C) 2018 EScience Press. All rights reserved.

\section{INTRODUCTION}

Pakistan has a chronic fodder shortage, with two pronounced deficit periods. The most serious deficit period is from December to January, when the traditional winter fodders of berseem (Trifolium alexandrinum), shaftal (Trifolium resupinatum) and lucerne (Medicago sativa) are dormant. The other critical period is from May to June, when the summer fodders of maize (Zea mays), pearl millet (Penni setumglaucum), sorghum (Sorghum bicolor) and sorghum-Sudan grass hybrids (Sorghum vulgare var. sudanense) have only just begun growth, but the winter fodders are finished. Until recently, seeds of improved fodders, especially multicut oats, have not been available, so there has been a scarcity of fodder in terms of both quantity and quality.

Oats (Avena sativa L. and Avena byzantina Koch) rank fifth in terms of global cereal production and are widely used as a complementary crop for sowing forage legumes (Dost, 1997). They are mainly grown in temperate and cool subtropical environments. Avena sativa is a fast growing and high yielding winter fodder crop. It is highly palatable, nutritious and energy rich fodder and can be fed to animals either in the form of green fodder or after converting into good quality hay/silage (Dar et al., 2007). In Pakistan, oat is an important winter fodder, both in irrigated and rainfed areas. The green yield of local oat landraces under rainfed conditions is about $20 \mathrm{t}$ ha- 1 (Ahmad et al., 2008). Recently, the oat plantation at 
different locations of Multan were found to be suffered with a new type of disease known as leaf spot of oat. Therefore, the present research was conducted to confirm the etiology of this new disease and to determine its incidence and intensity in different areas of Multan.

\section{MATERIALS AND METHODS}

Survey and study site: A comprehensive survey of various oat fields was carried out at some localities of Multan to determine the disease severity and incidence of leaf spot disease of oat in the field.

Isolation, identification and culturing of pathogen: The collected samples were brought to the Mycology Laboratory of Department of Plant Pathology, Bahauddin Zakaria University, Multan for isolation of disease causing pathogen. Five pieces, 3-5 mm long, were excised from samples, surface-sterilized in $1 \% \mathrm{NaOCl}$ solution for two minutes, washed twice with sterilized distilled water, dried on sterile kraft paper and placed in Petri dishes containing potato dextrose agar (PDA) medium. These plates were incubated at $25^{\circ} \mathrm{C}$ and received a light of 600 lux. The growing fungi were identified based on the specific characteristics (Minuzzi and Lopes, 2015).

\section{Pathogenicity test of the causal pathogen}

Four fungal isolates were isolated from naturally infected oat leaves showing leaf spot symptoms. Pathogenicity tests of these four isolates were carried out under greenhouse conditions at Department of Plant Pathology, Bahauddin Zakariya University, Multan. The inoculum was prepared by culturing each of the isolate on PDA medium at $27 \pm 1^{\circ} \mathrm{C}$ for 7 days. Ten mililitre of distilled sterilized water was then added to each plate and colonies were carefully scraped with a sterile needle. The resulting conidial suspension from each isolate was adjusted to $5 \times 10^{6}$ spores $/ \mathrm{ml}$ and used for the inoculation of 10 oat plants using an atomizer. After inoculation, plants were covered with polyethylene bags for 48 hours to maintain high humidity conditions. After 48 hours, bags were removed, and plants were kept under greenhouse conditions. Pots were arranged in a completely randomized design under greenhouse conditions. Two weeks after inoculation, disease severity was recorded. The experiment was repeated twice.

Disease incidence: The disease incidence was recorded by using the following formula:

Disease incidence $(\%)=\frac{\text { Number of infected plants }}{\text { Total Number of plants observed }} \times 100$

Disease severity: Disease severity was determined on the basis of 0-11 modified scale of Horsfall and Barratt (1945) given in Table 1 and calculated by the given formula:

Disease severity (\%)

$$
\begin{aligned}
& =\frac{\text { Sum of all the score of individual plants }}{\text { Total no. of plants observed }} \\
& \times \frac{100}{\text { Maximum scale }}
\end{aligned}
$$

Statistical analysis: The collected data were subjected to analysis of variance (ANOVA) using SAS® 2002. Treatment means were compared using Fisher's least significant difference test at $\mathrm{P}=0.05$ and New Duncans Multiple Range Test (DMRT).

Table 1: Modified disease rating scale (Horsfall and Barratt, 1945).

\begin{tabular}{clc}
\hline Score & Symptoms & Infection percentage \\
\hline 0 & Round to elongate or diamond-shaped spots or blotches & $0-10$ \\
1 & Round to elongate or diamond-shaped spots or blotches coalese & $11-20$ \\
3 & Lesions turn yellowish to light brown or chocolate brown & $21-30$ \\
5 & Lesions turn yellowish to light brown or chocolate brown & $31-50$ \\
7 & Lesions are surrounded by a band of dull brown color & $51-60$ \\
9 & Minute black dots, scattered in the center & $61-80$ \\
11 & Whole leaf depicts the picture of spots & $81-100$ \\
\hline
\end{tabular}

\section{RESULTS}

Alternaria alternata was frequently isolated from the affected portions of the collected oat plants. Four isolates of A. alternata were purified and maintained on PDA for further study (Figure 1).

Pathogenicity test: All the tested isolates of A. alternata were able to infect oat plants causing typical leaf spot symptoms with different degrees of disease severity in greenhouse conditions (Figure 2).

Among these four isolates, the isolates B-2 and D-4 were highly pathogenic and caused the highest disease severity (Figure 3). 


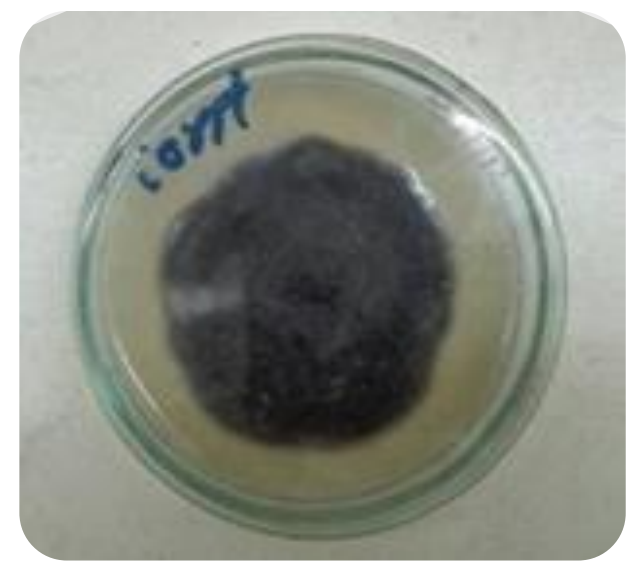

Figure 1. Culture of Alternaria alternate.

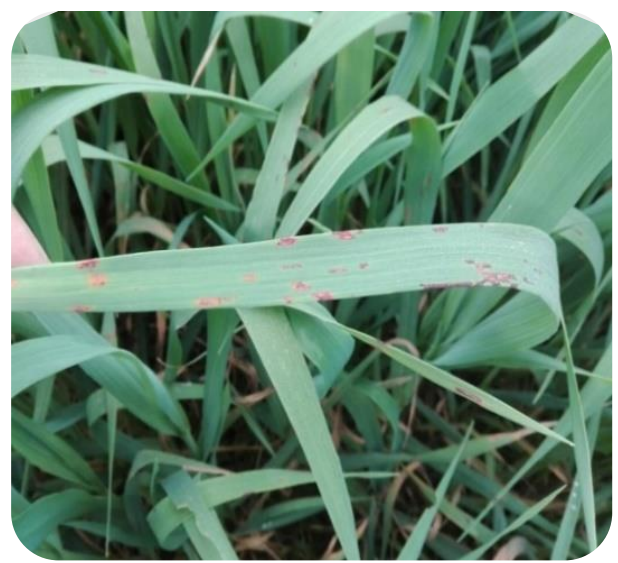

Figure 2. Alternaria leaf spots on oat leaves.

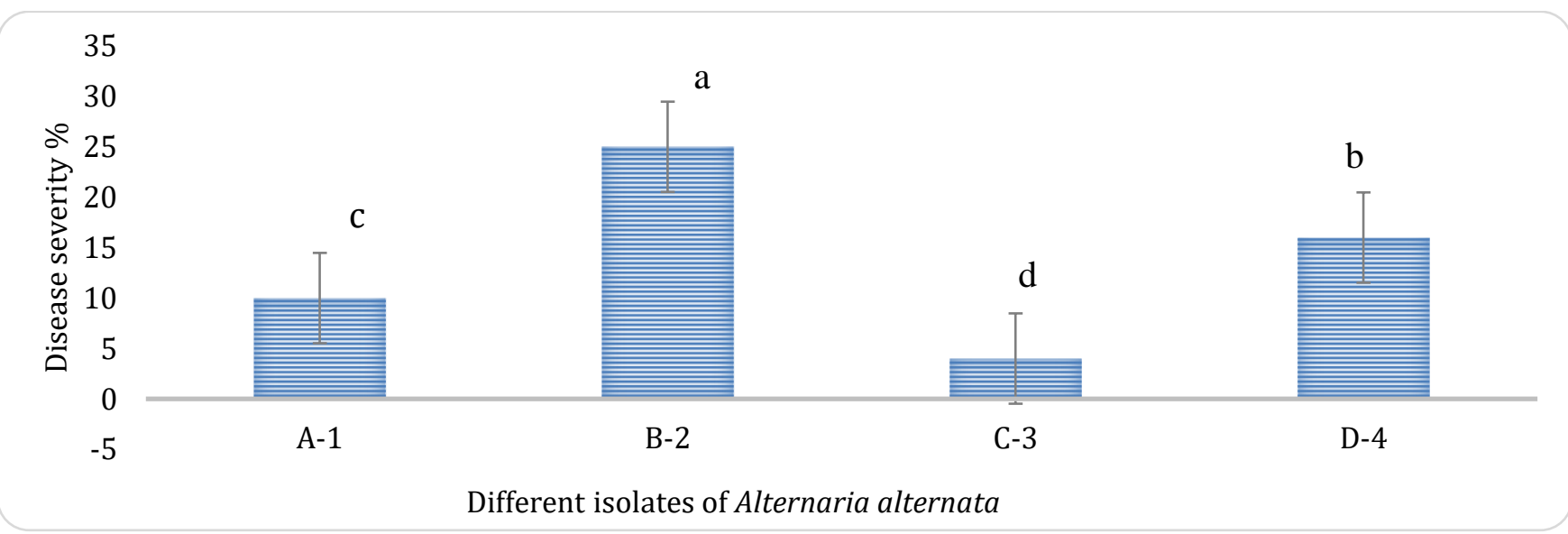

Figure 3. Pathogenicity tests of four isolates of Alternaria alternata on oat plants under greenhouse.

Disease incidence of oat leaf spot at various locations: Results showed that the maximum disease incidence of $51.99 \%$ was recorded at Band Bosan followed by $43.33,31.33$ and $27.66 \%$ incidences at
Raza Abad, Basti No and Lutfa Abad respectively (Figure 4). The variation in the disease incidence might be due to the farmer's practices and intercropping with the fodder crop.

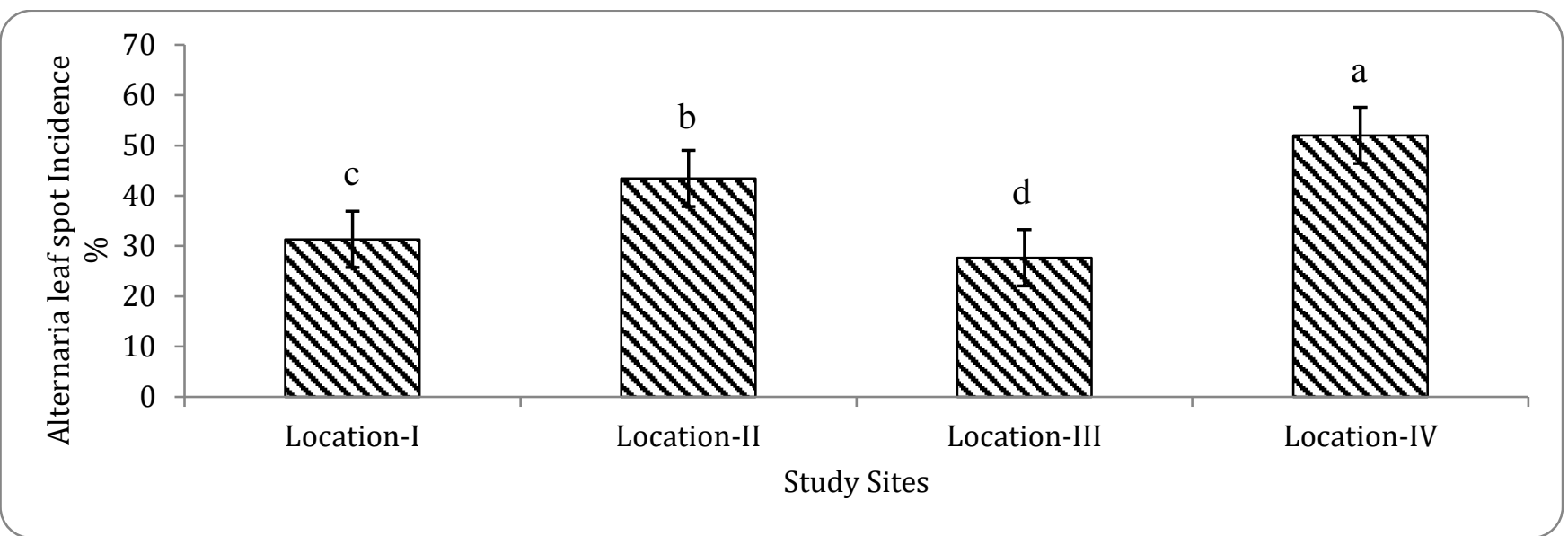

Figure 4. Disease incidence of Alternaria leaf spot of oat at selected sites in Multan. Location-I (Basti No), Location-II (Raza Abad), Location-III (Lutfa Abad) and Location-IV (Band Bosan). 
Disease severity of oat leaf spot at selected locations: Statistical analysis showed that the maximum severity of disease was recorded on location IV (Band bosan) with
31.99\% followed by location II (Raza Abad) with 21.66\%, location I (Basti No) with $11.33 \%$ and location III (Lutfa abad) with $7.33 \%$ (Figure 5).

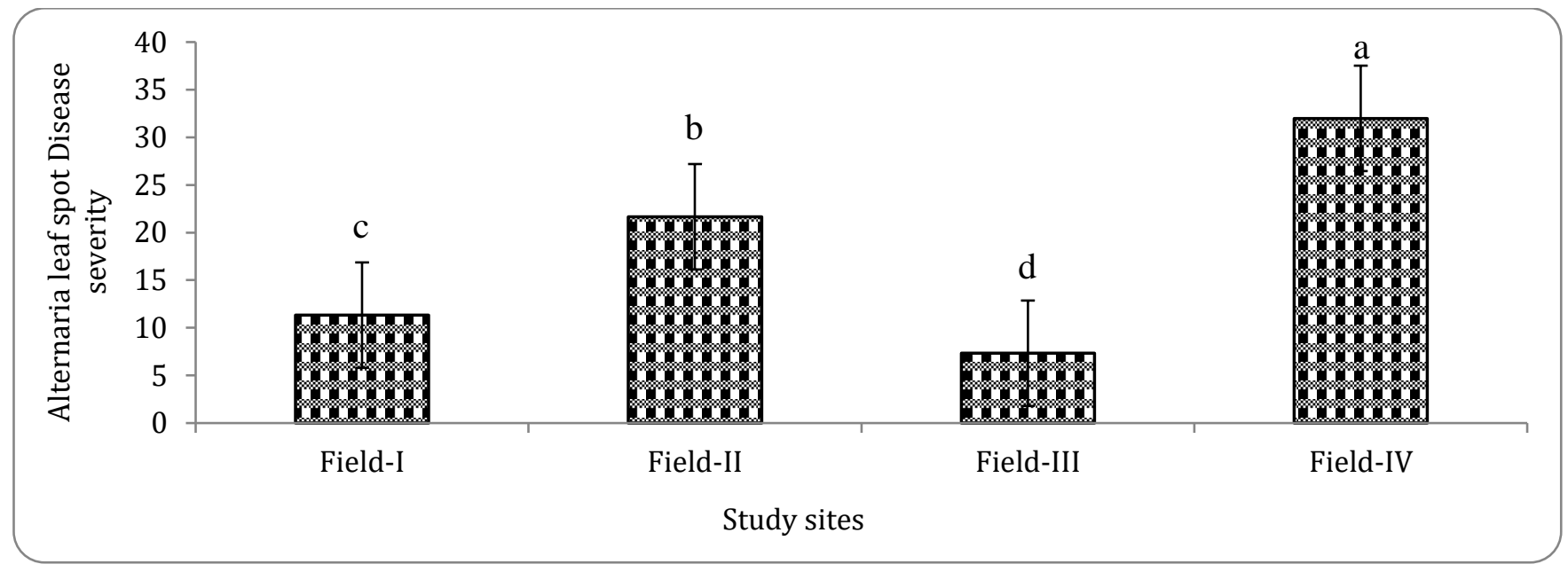

Figure 5. Disease severity of Alternaria leaf spot of oat at selected sites in Multan. Location-I (Basti No), Location-II (Raza Abad), Location-III (Lutfa Abad) and Location-IV (Band Bosan).

\section{DISCUSSION}

In global cereal production, oats are widely grown as a complementary crop for forage legumes (Dost, 1994). In Pakistan, they are an important winter fodder in both irrigated and rain fed areas. During the current research, some studies on the isolation, identification and prevalence of Alternaria leaf spot of oat at selected locations of Multan was carried out. To the best of our knowledge it may be the first outbreak report of Alternaria leaf spot of oat in Multan. Alternaria sp., causing leaf spot or seedling blotch, is a seed-borne pathogen; the fungus also survives on host debris, is a long-cycled fungus. Results showed that the maximum disease incidence was recorded on location IV (Band bosan) where $51.99 \%$ disease incidence was reported followed by location II (Raza abad) where 43.33\% incidence was found. Similarly, location III (Lutfa abad) showed 27.66\% and location I (Basti No) depicted $31.33 \%$ incidence. The variation in the disease incidence of the leaf spot of oat might be due to the farmer's practices and intercropping with other crops. Disease severity results showed that the maximum severity of disease was recorded on location IV (Band bosan) with $31.99 \%$, followed by location II (Raza abad) with $21.66 \%$, location I (Basti No) with $11.33 \%$ and location III (Lutfa abad) with $7.33 \%$. It is, therefore, concluded that necessary control strategies must be adopted to prevent Alternaria leaf spot from becoming widespread in the oat growing areas.

\section{REFERENCES}

Ahmad, G., Ansar, M., Kaleem, S., Nabi, G., Hussain, M., 2008. Performance of early maturing oats (Avena sativa L.) cultivars for yield and quality. Journal of Agricultural Research 46, 341-346.

Dar, N.A., Khan, H.U., Ganai, N.A., Burman, K., 2007. Evaluation studies on the dry matter production and quality of annual and perennial grasses. Forage and Grazing Lands 10, 1-5.

Dost, M., 1994. Quarterly report on fodder component. UNDP/FAO project PAK/86/027. FAO/UNDP, Gilgit, Pakistan.

Dost, M., 1997. End of assignment report on fodder component UNDP/FAO project Pakistan, 86/027. FAO/UNDP. Gilgit, Pakistan.

Horsfall, J.G., Barratt, R.W., 1945. An improved grading system for measuring plant diseases. Phytopathology 35, 655.

Minuzzi, R.B., Lopes, F.Z., 2015. Desempenho agronômico do milho em diferentes cenários climáticos no Centro-Oeste do Brasil. Revista Brasileira de Engenharia Agricola e Ambiental-Agriambi 19, 734-740. 